Disponível em:

http://editora.unoesc.edu.br/index.php/race

RACE, Joaçaba, v. 17, n. 2, p. 643-666, maio/ago. 2018

\title{
CAFÉS ESPECIAIS, GOVERNO E MERCADO: REFLEXÕES PARA A IMPLEMENTAÇÃO DE POLÍTICAS DE VALORIZAÇÃO DA MARCA “CAFÉS DO BRASIL”
}

Special cafés, government and market: reflections for the implementation of valuation policies of "Cafés do Brasil"

Marco Aurélio dos Santos

E-mail: marcooliveira_santos@yahoo.com.br Mestre em Agronegócio pela Universidade Federal do Rio Grande do Sul; Doutorando no Programa de Pós-graduação em Extensão Rural da Universidade Federal de Viçosa; Professor no Curso de Administração da Universidade Federal do Oeste do Pará, Campus Alenquer. Endereço para contato: Rua Dr. Pedro Vicente, 270, Luanda, 68200-000, Alenquer, Pará, Brasil.

\section{Marco Aurélio Marques Ferreira}

E-mail: marcoufv1@gmail.com

Pós-doutor em Administração Pública pela Rutgers University (EUA); Doutor em Economia Aplicada pela Universidade Federal de Viçosa; Professor no Departamento de Administração e Contabilidade da Universidade Federal de Viçosa.

Artigo recebido em 09 de março de 2018. Aceito em 09 de julho de 2018. 
Resumo

O objetivo com este artigo foi fazer um levantamento histórico descritivo dos fatores que podem afetar o posicionamento da marca "Cafés do Brasil” como símbolo de qualidade, sabores, diversidade de origens e sustentabilidade dos cafés produzidos nas diferentes regiões do País. Para tanto, recorreu-se a uma revisão de literatura - livros e revistas que abordaram o histórico de políticas públicas aplicadas à cafeicultura e seus preponentes - atrelada à revisão acerca de análise de política pública, para fazer inferências. Observou-se que a monopolização política, econômica e social exercida pelo café no início do século XIX favorecia a ação direta do Estado. Ao contrário do que acontecia no passado, atualmente o café é apenas outra atividade econômica, que requer condições políticas favoráveis ao desenvolvimento de habilidades que ampliem a vantagem competitiva local. Conclui-se que a implementação de políticas públicas na cadeia do café passou a ser dependente da dinâmica institucional nas regiões produtoras. Assim, as políticas que negam esse paradigma estão sujeitas à ineficiência e, consequentemente, demandam esforços para reorientá-las.

Palavras-chave: Análise política. Fatores históricos políticos. Grupos de interesse. Agronegócio.

Abstract

The objective of this article was to make a descriptive historical survey of the factors that may affect the positioning of the "Cafés do Brasil" brand as a symbol of quality, flavors, diversity of origins and sustainability of the coffee produced in different regions of the country. To do so, we resorted to a literature review - books and journals that addressed the history of public policies applied to coffee and its preponents - linked to the review about public policy analysis, to make inferences. It was observed that the political, economic and social monopolization exerted by the coffee in the early nineteenth century favored the direct action of the State. Contrary to what happened in the past, coffee is now just another economic activity, which requires political conditions conducive to the development of skills that enhance local competitive advantage. It is concluded that the implementation of public policies in the coffee chain has become dependent on the institutional dynamics in the producing regions. Thus, policies that deny this paradigm are subject to inefficiency and, consequently, require efforts to reorient them.

Keywords: Political analysis. Political historical factors. Interestgroups. Agribusiness.

\section{INTRODUÇÃO}

Delfim Netto (1966, p. 329) defendia, na obra O Problema do Café no Brasil, que “a política cafeeira que mais convém não é a que procura obter o máximo de dólares no curto prazo, mas aquela que assegura a receita máxima no longo prazo.” Desde o lançamento do estudo, em 1966, a agricultura evoluiu e a cafeicultura deixou de ser 
o motor econômico da nação e a fonte de poder da pequena oligarquia cafeeira. Entretanto, o café foi e ainda é uma problemática na vida econômica e política do Brasil.

O mercado cafeeiro passou por mudanças após a desregulamentação do mercado em 1989. As grandes empresas torrefadoras assumiram o papel de agentes coordenadores da cadeia. Os consumidores passaram a buscar produtos com maior valor agregado, diferenciados pela especialidade e sustentabilidade, quebrando a lógica da concorrência por preços dos cafés commodities, ampliando as oportunidades de emprego e renda (FEUERSTEIN, 2007; PONTE, 2002).

Essa dinâmica tem provocado uma revolução na cadeia agroindustrial do café (DAVIRON; PONTE, 2005; MAYER; GEREFFI, 2010; REHBEIN; SCHULER, 2015), e os reflexos são políticos e mercadológicos. O saldo dessas mudanças pode ser medido pela expectativa de crescimento de consumo: somente em 2014 foram consumidos 141 milhões de sacas e há uma expectativa de alcançar 175,8 milhões até 2020 (ICAFE, 2015; INTERNATIONAL COFFEE ORGANIZATION, 2014; UNITED STATES OF DEPARTMENT AGRICULTURE, 2014).

Contudo, certos países produtores têm enfrentado problemas com assimetria de informação por não conseguirem transmitir com clareza as características do produto, trazendo ineficiência para o mercado. Em um mercado com crescente apelo pela qualidade e sustentabilidade, é ascendente o papel da dispersão de informação à medida que cresce o interesse dos consumidores por atributos não observáveis nos produtos (VAN RIJSBERGEN et al., 2016; VERTINSKY; ZHOU, 2000). Essas mudanças têm obrigado os países produtores a se adaptarem aos novos padrões competitivos.

Contudo, certos países produtores têm enfrentado problemas com assimetria de informação por não conseguirem transmitir com clareza as características do produto, trazendo ineficiência para o mercado. Em um mercado com crescente apelo pela qualidade e sustentabilidade, é ascendente o papel da dispersão de informação à medida que cresce o interesse dos consumidores por atributos não observáveis nos produtos (VAN RIJSBERGEN et al., 2016; VERTINSKY; ZHOU, 2000). Essas mudanças têm obrigado os países produtores a se adaptarem aos novos padrões competitivos.

Embora o Brasil, maior produtor dessa commodity, tenha vantagem comparativa na produção dos mais variados tipos de café, a intervenção que se estendeu por quase um século ajudou a construir uma identidade de produtor de um tipo único de café, o "Café Tipo Santos” (SAES; NAKAZONE, 2002), fato que tem demandado uma estrutura organizacional e política capazes de auxiliarem as regiões produtoras no desenvolvimento de capacidades e competências para comunicar o diferencial dos cafés brasileiros. 
Atento a esse entrave, o Ministério da Agricultura adotou um programa de marketing, cujo objetivo é coordenar e direcionar ações que integrem todos os elos da cadeia produtiva para posicionar a marca "Cafés do Brasil” como símbolo de qualidade, sabores, diversidade de origens e sustentabilidade dos cafés produzidos nas diferentes regiões do País (MINISTÉRIO DA AGRICULTURA, PECUÁRIA E ABASTECIMENTO, 2012). Espera-se que o programa alinhe o setor ao novo padrão concorrencial e adicione valor ao café brasileiro, mirando uma atuação mais agressiva no mercado.

A implementação desse programa requer ações integradas e que a estrutura organizacional seja estreita e eficiente para garantir efetividade das ações. Assim, falhas no planejamento podem representar distanciamento dos resultados esperados (HILL; HUPE, 2002; VILLANUEVA, 1996). Essa iniciativa traz consigo os desafios de integrar todos os agentes envolvidos na cafeicultura brasileira acerca de um objetivo comum: fazer da marca “Cafés do Brasil” a identidade de um produto sustentável e com qualidade diferenciada daquela de grande produtor de café commodity (Tipo Santos).

Contudo, colocar essas ações em prática depende da cooperação de indivíduos com demandas e percepções diferenciadas sobre os objetivos a serem atingidos (GALLEGO; BARBIERI; GONZÁLEZ, 2017; REHBEIN; SCHULER, 2015). Desse modo, a efetividade política pode estar distante das demandas setoriais, expressando apenas a visão subjetiva que os policymakers têm da realidade (ROCHA, 2006). Nessa perspectiva, a efetividade política pode estar atrelada à lógica de construção dos programas políticos.

A construção de uma política pública está atrelada ao jogo de poder e à defesa de interesses em uma sociedade (EASTON, 1968; LOWI, 1972). Em sociedades nas quais todos os atores são equivalentes - assim, no padrão pluralista - todos têm chances de obter a decisão que lhes seja mais favorável (RUA, 1997). Portanto, a construção de uma política leva em consideração a capacidade de articulação e defesa dos interesses nas arenas políticas.

Diferentemente do que ocorre em sociedades como as citadas, naquelas em que há poucos atores atuantes nas arenas políticas, os resultados são previamente definidos pelos interesses das elites (elitismo), que controlam os recursos organizacionais da sociedade, ou pelos da classe dominante (modelo de classes), que controla os recursos produtivos (interesses econômicos) (ROCHA, 2006). O modelo elitista na construção das políticas é resultado das preferências e dos valores da elite. 
Nesse sentido, as políticas públicas passam a ser moldadas pelo jogo de interesse dos grupos poderosos da sociedade. As decisões políticas passam a refletir as ações e decisões dos indivíduos com o passar do tempo, configurando um processo incremental que se reforça ao longo do tempo (LOPES, 2013; PETERS, 2016). Logo, o melhor caminho para entender a efetividade do programa “Cafés do Brasil” é resgatar as históricas ligações entre cafeicultura, economia e política (DELFIM NETTO, 1966), dentro de uma perspectiva de análise de política pública.

A história dessa cultura pode fornecer a chave para indicar falhas entre o que foi planejado e os resultados a serem alcançados (HILL; HUPE, 2002; PIRES, 2009). Por meio da história se podem identificar possíveis variáveis da estrutura organizacional que oferecem uma visão clara dos desafios a serem superados para a efetividade desse programa público. Nesse sentido, o objetivo com este estudo foi fazer um levantamento descritivo dos fatores históricos que podem afetar a efetividade do programa “Cafés do Brasil”.

Espera-se que este trabalho possa ser um exemplo prático de como a história ganha relevância nos programas e projetos políticos, pois soluções ineficientes tendem a se perpetuar e a ser a raiz da ineficiência (GALA, 2003), exigindo esforços para reconduzir o objeto, o foco e o conteúdo da política pública (FREY, 2009; PASE; MELO, 2017).

Para alcançar o objetivo proposto, valeu-se de uma revisão de literatura acerca das políticas cafeeiras explícitas nas obras O Problema do Café no Brasil, de Delfim Netto (1966); Vida e Morte do Convênio de Taubaté: a primeira valorização do café, de Holloway (1978); e Das Oligarquias Agrárias ao Predomínio Urbano-Industrial: um estudo do processo de formação de políticas agrícolas no Brasil, de Mueller (1983), bem como nas edições comemorativas dos 70 anos de política agrícola no Brasil e dos 150 anos do Ministério da Agricultura, Pecuária e Abastecimento (MAPA) da Revista de Política Agricola, de tal modo que, atreladas à análise de políticas públicas e à caracterização das regiões produtoras, fizeram-se as inferências acerca do tema proposto.

Este artigo está dividido em quatro partes, contando com esta contextualização geral. Na segunda parte, busca-se fazer um resgate histórico, evidenciando o sistema político em diferentes momentos do tempo, a estrutura de poder e seus reflexos para a formulação e implementação dos programas públicos para solucionar os problemas econômicos, sociais e políticos oriundos das crises cafeeiras e as mudanças ocorridas nesse sistema ao longo do tempo. Na terceira parte, expressa-se como as 
mudanças se refletiram na estrutura de poder, bem como no sucesso da implementação das políticas voltadas à cafeicultura, e, por fim, as considerações finais.

\section{PRECEITOS HISTÓRICOS DA INTERVENÇÃO}

O comércio exterior sempre foi e é um braço forte da vida econômica brasileira. Historicamente as culturas agroexportadoras foram a base dessas relações comerciais. O Governo brasileiro sempre teve a preocupação de ter uma secretaria para cuidar dos negócios da agricultura, comércio e obras públicas (MUELLER, 2010). No período imperial havia a Secretaria dos Negócios da Agricultura, Comércio e Obras; contudo, a centralização do poder imperial limitava a ação estratégica da secretaria junto à cafeicultura.

No período imperial o café era comercializado in natura e posteriormente torrado em domicílio, tanto que a qualidade do produto era condicionada à habilidade individual das famílias. A partir de 1865 algumas empresas se especializaram na torra e venda do café em pequenas quantidades embaladas, impulsionando o consumo e estabelecendo as bases para a diferenciação e coordenação da cadeia (HOLLOWAY, 1978).

A entrada dessas empresas impulsionou a demanda por cafés. Por apresentar boas condições de clima e solo, o Estado de São Paulo passou a ser o principal fornecedor do mercado mundial. Atrelada à expansão do consumo, a cultura se expandiu pelos Estados de Minas Gerais e Rio de Janeiro e se consolidou como o principal produto da economia brasileira no fim do século XIX. A notoriedade no mercado externo fez a cafeicultura monopolizar a vida política e econômica do País.

Com a crise do Império, houve um enfraquecimento do Governo central, abrindo-se espaço para a oligarquia cafeeira assumir as principais cadeiras da estrutura democrática recém-instituída em 1889, caracterizando-se um elevado grau de autonomia na condução das políticas cafeeiras (MUELLER, 2010, 1983). Tal monopólio conquistado pela oligarquia cafeeira produziu uma centralização decisória e uma disciplina hierárquica que favoreciam a formulação e implementação das políticas voltadas para a defesa do setor cafeeiro (FURTADO, 2005; HOLLOWAY, 1978; DELFIM NETTO, 1966).

A atuação da oligarquia cafeeira se fazia mais intensa em momentos de crise, tanto que, para Delfim Netto (1966), o problema do café era um problema de mercado, mas a solução pelo sistema de preço foi abandonada em favor de uma classe que sofria os azares da atividade. Assim, o ambiente decisório era marcado pelo protecionismo 
comercial da classe dominante, que pressionava por uma intervenção federal de curto prazo (HOLLOWAY, 1978). A pressão dos cafeicultores resultou na assinatura do Convênio de Taubaté, em 1906.

O Convênio estipulava as regras para valorização e maximização das receitas no curto prazo, contrariando a ideia de que as políticas cafeeiras mais pertinentes são as que asseguram máximas divisas no longo prazo, não a que produz o máximo de receita no curto prazo (DELFIM NETTO, 1966, p. 329). Assim, criou-se uma rede que reuniu banqueiros e negociantes para iniciar um plano de valorização, para retirar do mercado o excedente produzido, e restringia o plantio de novas lavouras, visando a elevar os preços no mercado (DELFIM NETTO, 1966). Logo, a rede passou a determinar o jogo político de acordo com seus interesses de curto prazo (HILL; HUPE, 2002; LOWI, 1964).

A rede alcançou os resultados esperados e no longo prazo assumiu caráter funcional ao harmonizar as demandas do setor cafeeiro com as políticas de coordenação e planejamento sob a perspectiva macroeconômica (SAES, 1995). Nesse sentido, as políticas públicas eram elaboradas para atender aos interesses da elite cafeeira, explicitando um reflexo da estrutura institucional (BACHRACH; BARATZ, 2011; POLSBY, 1960), atrelada à dependência das exportações de café para equilibrar a economia.

O sucesso na implementação dessa política somente foi possível graças a três fatores primordiais que reduziam a complexidade na elaboração, sobretudo na implementação das políticas públicas. Primeiro, a posição monopolística que o Brasil ocupava no cenário mundial. Em meados de 1906 o Brasil era responsável por cerca de três quartos da oferta mundial. Essa posição colocava o País em uma condição favorável para impor seus interesses frente ao mercado, visto que suas decisões tinham grande impacto no comércio dessa commodity. Mesmo que os torradores quisessem impor restrições, eram limitados pela posição ocupada pelo Brasil.

Segundo, o café detinha o monopólio da vida econômica da nação. A vida econômica girava em torno do bom funcionamento dos preços do mercado cafeeiro. Por fim, se o café era o principal produto da economia, quem o produzia tinha grande poder econômico, logo um poder político. Nesse sentido a oligarquia cafeeira impunha certa disciplina na formulação, bem como na implementação das políticas públicas. Desse modo, o sucesso das políticas de sustentação de preços foi inevitável, tanto que tornou a se repetir nos anos de 1909, 1917, 1921 e 1924, evidenciando um processo incremental, saindo de uma ação pontual e se efetivando como programa 
governamental (BAUMGARTNER; JONES, 1991; DIMAGGIO; POWELL, 1983; SOUZA, 2002).

No entanto, a crise de 1929 provocou recessão econômica e desvalorização da commodity nos principais mercados consumidores, produzindo sérias dificuldades a uma economia dependente das exportações do café. Tais dificuldades levaram a profundas mudanças no cenário político-administrativo. Washington Luiz, então Presidente da República, recusou-se a continuar com a defesa do principal produto da economia, deflagrando conflito entre frações da classe dominante pelo controle político do Estado (BACHRACH; BARATZ, 2011; BUENO, 2007; STONE, 1989).

Esses conflitos representaram a ruptura na estrutura política que se iniciara com a República. Tal ruptura representou uma janela de oportunidade para o surgimento de novos grupos que impuseram uma reestruturação político-administrativa, marcando uma mudança no direcionamento e no papel da cafeicultura no sistema político e econômico nacional (IANNI, 1973). Nesse processo há uma descentralização do poder entre as novas redes, como a do açúcar, algodão, comércio e indústria, aumentando a complexidade nas decisões e ações.

Essa fragmentação do poder contribuiu para a criação de uma arena de debates mais conflituosa, demandando mais persuasão e consenso nas questões públicas. Logo se evidenciou o surgimento de uma estrutura de poder mutável, contrariamente às ideias preconizadas pelos elitistas, de que a estrutura de poder é estável, cada qual com sua estrutura política, seus processos, membros e conflitos grupais (BAUMGARTNER; JONES, 1991; LOWI, 1964; SECCHI, 2011).

O novo governo, de caráter centralizador e intervencionista, presidido por Getúlio Vargas, transferiu para o Governo Federal a política de defesa do café e em 1931 criou o Conselho Nacional do Café (CNC); restringiu o plantio de novas áreas, visando a equilibrar a oferta e demanda para alcançar preços compensadores (COELHO, 2012). Tais medidas emanavam de um novo planejamento econômico focado no desenvolvimento urbano-industrial pautado no equilíbrio macroeconômico. Assim, a formulação de políticas voltadas não apenas para a cafeicultura, mas para toda a agricultura, passa a ter um caráter predominantemente setorial, baseado no produto.

Tais ações passaram a se concentrar no Ministério da Agricultura. Contudo, a ação desse órgão era limitada pelo foco no desenvolvimento urbano-industrial, tornando-as ocasionais e pontuais, obrigando a rede a manter a pressão para que seus interesses fossem atendidos (MUELLER; MUELLER, 2010). Mesmo enfraquecido pela crise, o café ainda era a espinha dorsal da economia, e a defesa do cafeicultor 
representaria bem mais do que uma política clientelista, passava a combater o desemprego nos demais setores da economia (FURTADO, 2005).

A defesa do cafeicultor rompe com a estabilidade das políticas incrementais distributivas focadas apenas nos interesses de um grupo social (SOUZA, 2002), no caso a oligarquia cafeeira, e se configura como um verdadeiro programa de fomento à renda nacional (FURTADO, 2005). Tal mudança representou bem mais do que o enfraquecimento das políticas clientelistas que amparavam a elite cafeeira. A mudança representou uma maior intervenção estatal na economia e um projeto de industrialização que buscava superar a dependência econômica.

Apesar disso, a sustentação do preço permaneceu, dada a importância do café para o País, mas o foco da política se reduziu ao domínio da rede do café (MUELLER, 2010; DELFIM NETTO, 1966), evidenciando uma ruptura na estabilidade das políticas macrossetoriais. A partir de então as ações e políticas destinadas ao setor agrícola se fundamentaram na disponibilização de crédito e na garantia de renda aos produtores (CUNHA, 2010; TIMM; ARAUJO, 2010; WEDEKIN, 2005). Imediatamente a cafeicultura, assim como a agricultura, passou a desempenhar um papel secundário na agenda política, que se tornará centralizada, intervencionista e orientada para a industrialização. Assim a rede foi enfraquecida, fato que dificultou a defesa dos interesses, não apenas da cafeicultura, mas da economia agrícola frente aos novos interesses urbanos industriais.

Mesmo enfraquecida, a cafeicultura ainda era a principal fonte de divisas do Governo Federal, tanto que em 1952 foi criado o Instituto Brasileiro do Café (IBC), visando a dar maior autonomia na condução da política cafeeira (COELHO, 2012). O IBC buscou estruturar um acordo envolvendo os países produtores e consumidores em um novo plano de valorização cafeeira. Somente em 1960 se assinou o Acordo Internacional do Café, envolvendo países produtores e consumidores, pelo qual os países concordavam com a determinação de preços, qualidade e cotas de mercado. Assim, de um plano pontual que buscava apenas agir sobre a comercialização, estabeleceram-se complexas redes de ações e de reações que poderiam comprometer a efetividade das políticas econômicas nacionais (SAES; NAKAZONE, 2002).

O acordo somente foi possível pelo papel desempenhado pelo Brasil nas negociações. Muitas vezes o País se sujeitou a ser um ofertante residual, ou mesmo aceitou reduzir suas cotas de exportação em prol do sucesso da política. Os resultados dessa ação foram redução da parcela de mercado e perda do monopólio, que até então era um ponto importante em favor do Brasil na imposição dos interesses nacionais. 
Em 1964 houve o Golpe Militar, que introduziu um modelo de desenvolvimento pautado na substituição de importações, bem como na modernização da agricultura para diversificar as exportações. Nesse período ocorreu um declínio das redes de produtos e um fortalecimento de uma rede abrangente de políticas voltadas para a captura de renda e condições favoráveis de crédito que subsidiavam a modernização agrícola (MUELLER, 2010).

Cabia à cafeicultura subsidiar a industrialização e a formação dos complexos agroindustriais. Para tanto, o IBC passou a coordenar a dinâmica e o desempenho de cada segmento da cadeia por meio de um processo hierarquicamente autoritário, rígido para garantir o sucesso da política de valorização cafeeira. Esse bureau ofertava toda a infraestrutura de serviço necessária ao bom desempenho do setor.

O IBC apontava todas as estratégias de preços, oferecia toda a infraestrutura de serviço e controlava autoritariamente as ações da cadeia, o que, consequentemente, limitou o aprendizado e estimulou a dependência institucional, fato que contribuiu para uma eficiente coordenação que garantiu as divisas necessárias para a industrialização, porém com baixa integração vertical entre os diferentes elos da cadeia produtiva.

Esse modelo de coordenação, que perdurou até 1989, foi eficiente para produção e comercialização da commodity. O resultado dessa coordenação foi a formação de uma identidade e cultura de grande produtor de um tipo único de café, o "Café Tipo Santos” (SAES; NAKAZONE, 2002). Com isso, após a desregulamentação do mercado em 1989, os torrefadores passaram a impulsionar a cadeia produtiva tendo como base as necessidades do mercado pautadas em produtos diferenciados pela qualidade e sustentabilidade (HUMPHREY; SCHMITZ, 2001; PONTE, 2002). Nesse ínterim a identidade do café nacional passou a não ser mais compatível com o novo paradigma concorrencial que privilegia a qualidade em vez da quantidade.

No entanto, o resultado do crescimento acelerado da economia culminou com a crise, no início dos anos 1980, que repercutiu em todos os setores da economia. O reflexo foi a redução dos gastos com as políticas agrícolas, a promoção de mudanças na estrutura político-administrativa, a liberalização comercial, as privatizações e a desregulamentação do mercado cafeeiro (CHADDAD; JANK; SIDNEY, 2006). Com o fim das atividades do IBC em 1989, extinguiu-se toda a infraestrutura de serviço e de apoio que coordenava a cadeia. Sem um agente coordenador, os elos da cadeia começaram a trilhar os próprios caminhos. 


\section{A EMERGÊNCIA DE UMA NOVA ESTRUTURA ORGANIZACIONAL APÓS 1980}

A crise de 1980 produziu um cenário de incerteza e instabilidade na nação que somente foi revertido com o Plano Real, em 1994. Nesse meio tempo o liberalismo econômico pressionava o abandono de posturas ativas e intervencionistas em prol da livre circulação de mercadorias. As tarifas foram paulatinamente abandonadas, expondo setores protegidos à concorrência externa (GURGEL; BITENCOURT; TEIXEIRA, 2002; VALVERDE; ZAUZA; SILVA, 1999), impondo novas regras redutoras das distorções comerciais (JOSLING et al., 1994; TEIXEIRA; HOLLOWAY, 1998).

Essas mudanças obrigaram a agricultura, como um todo, a responder mais eficientemente à nova concorrência internacional. Contudo, a política que deveria dar suporte aos produtores enfrenta diferentes problemas. As responsabilidades conferidas ao Ministério da Agricultura foram descentralizadas entre diferentes órgãos, configurando uma estrutura institucional complexa e desarticulada (CUNHA, 2010; OCDE, 2005). A descentralização criou uma estrutura institucional que abriga um Ministério da Agricultura para os agricultores patronais e outro para a agricultura familiar, ambos competindo por recursos escassos, que são gastos com grupos específicos (CHADDAD; JANK; SIDNEY, 2006).

O resultado desse processo foi a transferência de serviços fundamentais, como a extensão rural, para os estados e municípios, sobrando para o Ministério da Agricultura a fiscalização e aferição de qualidade dos produtos, ao passo que Ministério do Meio Ambiente está mais preocupado em excluir áreas agrícolas do que desenvolver formas produtivas mais sustentáveis (ORGANIZAÇÃO PARA A COOPERAÇÃO E DESENVOLVIMENTO ECONÔMICO, 2005; TIMM; ARAUJO, 2010). Essa multiplicação de órgãos reflete mais a busca pelo poder do que uma organização político-administrativa eficiente e eficaz, capaz de alavancar o potencial das cadeias produtivas brasileiras (BACHRACH; BARATZ, 2011).

Essa complexa estrutura institucional pode ocasionar conflitos entre duas redes de políticas que têm visões diferentes, levando à paralisia do Estado (MUELLER, 2010; WEDEKIN, 2005). As novas redes envolvem participantes de diferentes complexos agroindustriais, organizados em associações com representantes em câmaras setoriais, configurando grupos organizados para pressionar a estrutura política em prol de seus interesses.

Essas redes têm a capacidade de dominar a tomada de decisão, fazendo valer seus interesses e ideias, levando as políticas públicas a serem, fundamentalmente, fun- 
ção da correlação entre o governo e as redes interessadas em decisões políticas específicas (NAVARRO, 2010). Portanto, as inter-relações estruturam o jogo político e seus resultados condicionam o tipo de política que está em jogo, de modo que provavelmente as relações políticas sejam distintas, mas guiadas pelos interesses particulares (BAUMGARTNER; JONES, 1991; LOWI, 1964). Assim, as mudanças institucionais e as relações intergovernamentais passam a determinar o resultado do jogo, que inevitavelmente sofre interferência das metas preestabelecidas ou dos tipos de inter-relações mantidas entre as redes (HILL; HUPE, 2002).

Com a desregulamentação do mercado em 1989, o poder da cadeia do café migrou para as empresas de torrefação, que passaram a definir o que, como e quanto produzir, introduzindo uma nova curva de aprendizado no sistema cafeeiro (BACON, 2005; PONTE, 2002; REHBEIN; SCHULER, 2015). No entanto, a cadeia produtiva brasileira estava acostumada com um bureau que predizia todas as ações, mostrando-se em um primeiro instante incapaz de responder às novas exigências mercadológicas, fato que levou diferentes redes representativas a ocupar o espaço deixado pelo IBC. O trabalho desses autores produziu e ainda vem produzindo transformações graduais na cafeicultura nacional. As redes vêm introduzindo adaptação produtiva e organização horizontal dos produtores para agregar valor e transmitir informações coerentes ao longo da cadeia, para entrar na cadeia de valor das grandes empresas de torrefação que impulsionam essa cadeia (GEREFFI, 1999; GEREFFI et al., 2001; GEREFFI; HUMPHREY; STURGEON, 2005).

O foco das redes é desenvolver as particularidades das regiões produtoras e a formação de clusters regionais para coordenar a adaptação de forma planejada. Ao valorizar as características locais, as redes trabalham para promover as marcas regionais usando elementos de valor diferenciado capazes de atrair a atenção do público, como se pode distinguir a partir do Quadro 1: 
Cafés especiais, governo e mercado: reflexões para a implementação de políticas...

Quadro 1 - Caracterização do posicionamento da oferta da regional ${ }^{1}$

\begin{tabular}{|c|c|c|c|c|c|}
\hline Região & Coordenador & Valores & Produção & $\begin{array}{c}\text { Característica do } \\
\text { café }\end{array}$ & Certificações \\
\hline $\begin{array}{l}\text { Alta Mo- } \\
\text { giana }\end{array}$ & \begin{tabular}{|l|} 
Associação dos \\
Produtores de \\
Cafés Especiais \\
da Alta Mogiana
\end{tabular} & $\begin{array}{l}\text { Responsabili- } \\
\text { dade social e } \\
\text { ambiental }\end{array}$ & $\begin{array}{l}\text { Familiar, mas } \\
\text { com presença } \\
\text { de grandes } \\
\text { propriedades }\end{array}$ & $\begin{array}{l}\text { Cafés naturais, des- } \\
\text { cascados e despol- } \\
\text { pados, marcantes } \\
\text { frutados, cremosos } \\
\text { aveludados, acidez } \\
\text { média a muito } \\
\text { equilibrada }\end{array}$ & $\begin{array}{l}\text { Indicação de proce- } \\
\text { dência, UTZ Certi- } \\
\text { fied, Rainforest e 4c }\end{array}$ \\
\hline $\begin{array}{l}\text { Matas de } \\
\text { Minas }\end{array}$ & $\begin{array}{l}\text { Conselho das } \\
\text { entidades do } \\
\text { café das Matas } \\
\text { de Minas }\end{array}$ & $\begin{array}{l}\text { Cafés social- } \\
\text { mente justos e } \\
\text { ambientalmente } \\
\text { corretos, natu- } \\
\text { ralmente sus- } \\
\text { tentáveis, quali- } \\
\text { dade artesanal }\end{array}$ & Familiar & $\begin{array}{l}\text { Cafés naturais } \\
\text { descascados de } \\
\text { cereja, adocicados, } \\
\text { com diversidade } \\
\text { de sabores cítricos, } \\
\text { intensos, com notas } \\
\text { florais e cítricas, } \\
\text { encorpados a muito } \\
\text { encorpados, acidez } \\
\text { delicada e equili- } \\
\text { brada }\end{array}$ & $\begin{array}{l}\text { Certifica Minas, } \\
\text { UTZ Certified, } \\
\text { Rainforest }\end{array}$ \\
\hline $\begin{array}{l}\text { Norte } \\
\text { Pioneiro }\end{array}$ & \begin{tabular}{|l|} 
Associação de \\
cafés especiais \\
do norte pionei- \\
ro do Paraná
\end{tabular} & $\begin{array}{l}\text { Qualidade e } \\
\text { sustentabilidade }\end{array}$ & Familiar & Cereja despolpada & $\begin{array}{l}\text { Indicação de proce- } \\
\text { dência, UTZ Certi- } \\
\text { fied, Rainforest Fair } \\
\text { trade e } 4 c\end{array}$ \\
\hline $\begin{array}{l}\text { Oeste da } \\
\text { Bahia }\end{array}$ & $\begin{array}{l}\text { Associação dos } \\
\text { cafeicultores do } \\
\text { Oeste da Bahia }\end{array}$ & $\begin{array}{l}\text { Produtividade e } \\
\text { sustentabilidade }\end{array}$ & $\begin{array}{l}\text { Grupos empre- } \\
\text { sariais, peque- } \\
\text { nas e grandes } \\
\text { propriedades }\end{array}$ & $\begin{array}{l}\text { Boa fragrância e } \\
\text { aroma levemente } \\
\text { frutado e floral, } \\
\text { com excelente do- } \\
\text { çura e boa acidez }\end{array}$ & $\begin{array}{l}\text { Iniciou a indicação } \\
\text { geográfica, foco na } \\
\text { UTZ Certified }\end{array}$ \\
\hline $\begin{array}{l}\text { Manti- } \\
\text { queira de } \\
\text { Minas }\end{array}$ & $\begin{array}{l}\text { Associação dos } \\
\text { produtores de } \\
\text { café da Manti- } \\
\text { queira }\end{array}$ & $\begin{array}{l}\text { Tradição secu- } \\
\text { lar na produção } \\
\text { de cafés raros e } \\
\text { surpreendentes } \\
\text { com sustentabi- } \\
\text { lidade socioam- } \\
\text { biental }\end{array}$ & Familiares & $\begin{array}{l}\text { Café natural e café } \\
\text { cereja descascado }\end{array}$ & $\begin{array}{l}\text { Indicação e proce- } \\
\text { dência, Origem e } \\
\text { Qualidade - Man- } \\
\text { tiqueira de Minas - } \\
\text { IP, Certifica Minas }\end{array}$ \\
\hline Rondônia & $\begin{array}{l}\text { Cooperativa de } \\
\text { Produtores Ru- } \\
\text { rais para Ajuda } \\
\text { Mútua }\end{array}$ & $\begin{array}{l}\text { Tradição entre } \\
\text { matas }\end{array}$ & Familiares & $\begin{array}{l}\text { Café agroecológi- } \\
\text { co/sombreados }\end{array}$ & $\begin{array}{l}\text { Fair trade ECO- } \\
\text { CERT }\end{array}$ \\
\hline
\end{tabular}

\footnotetext{
${ }^{1}$ Para mais informações acessar o website das organizações regionais: Região do Cerrado Mineiro (2018), Cafés da Alta Mogiana (2018), Associação dos Cafeicultores do Oeste da Bahia (Abacafé) (2018), Associação de Cafés Especiais do Norte Pioneiro do Paraná (ACENPP) (2018), Mantiqueira de Minas (2018), Centro de Desenvolvimento Tecnológico do Café (CETCAF (2018) e Região das Matas de Minas (2018).
} 


\begin{tabular}{|c|c|c|c|c|c|}
\hline Região & Coordenador & Valores & Produção & $\begin{array}{c}\text { Característica do } \\
\text { café }\end{array}$ & Certificações \\
\hline $\begin{array}{l}\text { Cerrado } \\
\text { Mineiro }\end{array}$ & $\begin{array}{c}\text { Federação dos } \\
\text { cafeicultores do } \\
\text { Cerrado Mineiro }\end{array}$ & $\begin{array}{c}\text { Café de atitude, } \\
\text { ético, rastreá- } \\
\text { vel, com qua- } \\
\text { lidade e valor } \\
\text { compartilhado }\end{array}$ & Média a grande & \begin{tabular}{|c|} 
Aroma: intenso, \\
com notas varian- \\
do de caramelo \\
a nozes; Acidez: \\
delicadamente \\
cítrico, moderado a \\
encorpado, adoci- \\
cado com aspectos \\
de chocolate, longa \\
duração \\
\end{tabular} & $\begin{array}{l}\text { Denominação de } \\
\text { origem }\end{array}$ \\
\hline $\begin{array}{l}\text { Montanhas } \\
\text { do Espírito } \\
\text { Santo }\end{array}$ & Familiar & $\begin{array}{c}\text { Alto grau de } \\
\text { doçura desses } \\
\text { cafés; os cafés } \\
\text { descascados são } \\
\text { fantásticos, com } \\
\text { notas de flores } \\
\text { e frutas muito } \\
\text { doces }\end{array}$ & $\begin{array}{c}\text { Essencialmente } \\
\text { familiar, zelo } \\
\text { com qualidade } \\
\text { é inevitável }\end{array}$ & $\begin{array}{l}\text { UTZ Certified, } \\
\text { Rainforest }\end{array}$ & $\begin{array}{l}\text { Centro de Desen- } \\
\text { volvimento do Café }\end{array}$ \\
\hline
\end{tabular}

As redes locais buscaram explorar um conjunto de valores distintos, pautados nas características produtivas, o tipo de produtores que exercem as atividades, as características dos cafés e os valores norteadores das atividades para atrair a atenção do mercado. Ao atuar assim, as regiões induzem uma reestruturação produtiva que leva em consideração o contexto local. Portanto, a estrutura política envolta ganha maior complexidade, visto que a organização coletiva contribui com a defesa dos interesses locais, permitindo a substituição do ator governamental pelos atores locais, de tal modo que se faz induzir uma adaptação nos processos de implementação das políticas e programas de valorização voltados para a cafeicultura.

Imediatamente, há uma migração do modelo de formulação das políticas pautado nas elites, passando a um modelo pluralista com diversos centros de poder, sendo que nenhum deles é totalmente soberano (ROCHA, 2006). Outro elemento que corrobora para a explicação da complexidade de construção da políticas de valorização na atualidade é que o café já não tem mais a mesma importância econômica que a de outras épocas como ocorreu no período do Convênio de Taubaté, em 1906 (HOLLOWAY, 1978; DELFIM NETTO, 1966). Em 1906 a elite política usufruía do poder que a cafeicultura ofertava. Esse poder se dissipou a partir da revolução de 1930, dando lugar a uma estrutura política plural que passa a disputar o poder político em arenas mais complexas que as vigentes no início da implementação do plano de valorização em 1906. 
Com a desregulamentação mercadológica, aflorou um ambiente concorrencial, e a luta por interesses individuais se ancora em redes políticas interessadas em decisões políticas específicas; em muitos casos esses interesses individuais somente podem ser alcançados via ação coletiva, diferentemente do que ocorria no período de regulamentação, no qual o ambiente concorrencial era diminuto e exigia pouco investimento em novas habilidades para sobreviver. Portanto, a desregulamentação do mercado cafeeiro produziu um ambiente concorrencial que exige investimento em novas habilidades e conhecimentos para sobreviver. Desse modo, os subsistemas locais ancorados nas redes locais representam conflitos de interesses que esbarram na estrutura político-administrativa complexa, de maneira que os subsistemas locais representam um desafio para integrar todos os agentes envolvidos na institucionalização da nova identidade representativa da cadeia agroindustrial do café.

O desafio para a implementação da nova identidade do café brasileiro é oriundo da estrutura hierárquica que disciplinava a política cafeeira antes da desregulamentação. Enquanto o mercado era regulado, as políticas setoriais se passavam dentro de um modelo top-down, que passou a encontrar dificuldades nos sistemas políticos pela entrada de múltiplos atores (SECCHI, 2011), diferentemente do que ocorria no início do século XX. Assim, as decisões passam a depender mais da capacidade de negociação dos empreendedores políticos, o que não ocorria especificamente no início do século.

No início do século o Brasil ditava as regras do mercado, o café era o principal produto da economia, a elite dominante era um produto desse monopólio econômico, os problemas políticos e sociais eram oriundos dos problemas da cafeicultura. Logo, havia um alinhamento de interesses acerca dos problemas da cafeicultura, em que o Estado trabalhava para reduzir as incertezas do mercado cafeeiro para maximizar o bem-estar da nação.

Esse cenário facilitava a implementação das políticas públicas e da coordenação de todo o sistema cafeeiro, fazendo prosperar um eficiente modelo de comercialização da commodity, tanto que se deteriorou a imagem da cafeicultura nacional, expressando um limitante à competitividade. A nova realidade mercadológica preza pela resposta eficiente às concorrências e pela adequação às necessidades dos atores dominantes da cadeia de valor - que impõe especialização, segmentação e integração vertical -, as quais, uma vez alcançadas, reforçam os interesses e mantêm o grupo em um caminho equilibrado, o que representa um empecilho a uma eficiente coordenação conjunta para a institucionalização da marca nacional, e, logo, representa também 
uma restrição para o posicionamento da marca nacional, como se pode resumir por meio do Diagrama 1:

Diagrama 1 - Elementos estruturais da implementação

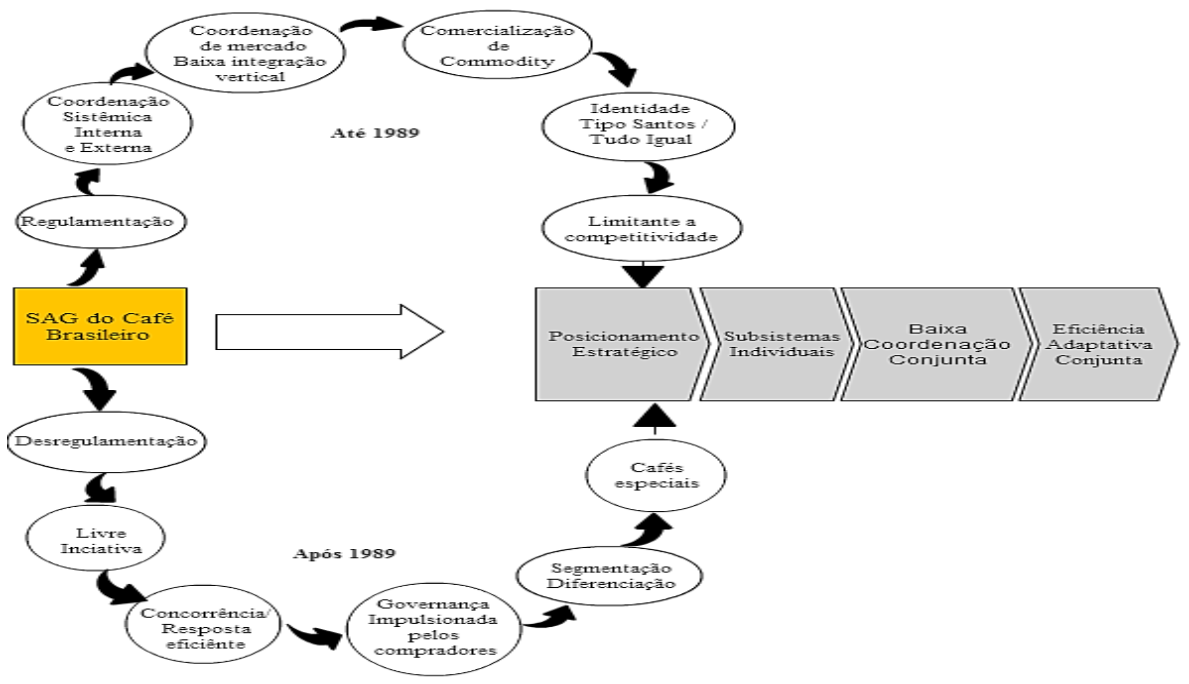

Fonte: Santos (2015).

Entende-se que a cadeia produtiva do café brasileiro, ao atuar por muito tempo regulado, criou uma identidade de grande produtor de um único tipo de café. Atualmente essa identidade dificulta a atração dos grandes compradores e do mercado especializado, os quais determinam as características dos produtos na cadeia de valor do sistema. As entidades representativas buscaram meios de agregar valor ao produto, saindo de uma situação de simples vendedor de commodity para atuar mais próximo do consumidor final, posicionando-se como região diferenciada. Os aprendizados coletivos nessas regiões aumentam as possibilidades de maximizar renda com a crescente demanda por cafés diferenciados.

\section{CONSIDERAÇÕES FINAIS}

Por intermédio deste trabalho foi possível ressaltar que a estrutura institucional que facilitava a implementação da política cafeeira foi se perdendo ao longo do tempo. A estrutura que garantia o monopólio econômico, político e social favorecia a implementação de políticas favoráveis à elite cafeeira. Entretanto, à medida que o 
café perdia o monopólio, uma nova estrutura de caráter pluralista passava a dominar a arena política, evidenciando um processo de disputa e negociação por espaço na agenda política.

Outro agravante à efetividade da implementação foi a diversidade produtiva que se instaurou após a desregulamentação do mercado em 1989. Novos atores passaram a coordenar a cadeia, dificultando a institucionalização do programa sob a ótica top-down, como se observou ao longo da história da indústria cafeeira. As entidades representativas locais, ao assumir o papel deixado pelo IBC, passaram não apenas a coordenar as ações locais, mas a defender os interesses regionais.

As organizações coletivas trouxeram complexidade para o ciclo de política pública, uma vez que as necessidades passaram a ser distintas e produzindo incerteza quanto aos resultados planejados e alcançados, diferentemente do que ocorria no período de intervenção, sobretudo no início e até meados da Revolução de 1930, quando o Brasil era o monopolista do mercado e o café era o principal produto da economia; os poderes político, econômico e social provinham dessa cultura.

Esse resultado é consequência direta do jogo de interesses dos grupos poderosos que dominam a arena política em busca de vantagens individuais. Para tanto, fazem alianças e usam estratégias que favorecem o alcance de seus objetivos. Assim, o que move o curso de ação é o poder e a habilidade dos grupos que detêm o poder decisório em um determinado problema político, o que fica evidente nos modelos pluralista e elitista. É certo que a ação política se passa em grupos, seja ela dada pelas preferências elitistas, seja construída a partir da barganha e de habilidades dos políticos (pluralista).

Nesse sentido, a monopolização política e econômica exercida pelo café no início do século XIX criou uma estrutura política que reforçava as ações e decisões elitistas dependentes do Estado, diferentemente do que ocorre atualmente, quando o café é apenas mais uma atividade econômica e que demanda a construção de redes políticas para alcançar condições que favoreçam o desenvolvimento de competências capazes de ampliar o diferencial competitivo regional. Conclui-se que atualmente a implementação de políticas na cadeia do café é dependente da dinâmica organizacional das regiões produtoras. Assim, as políticas que negam esse paradigma estão sujeitas à ineficiência e à inefetividade, bem como passam a demandar mais recursos públicos para reorientá-las. 


\section{REFERÊNCIAS}

ASSOCIAÇÃO DE CAFÉS ESPECIAIS DO NORTE PIONEIRO DO PARANÁ (ACENPP). Disponível em: <http://acenpp.blogspot.com.br/>. Acesso em: 20 jan. 2018.

ASSOCIAÇÃO DOS CAFEICULTORES DO OESTE DA BAHIA (ABACAFÉ). Disponível em: <http://abacafe.org.br/> Acesso em: 20 jan. 2018.

BACHRACH, P.; BARATZ, M. S. Duas faces do poder. Revista de Sociologia e Política, v. 19, n. 40, p. 149, 2011.

BACON, C. Confronting the Coffee Crisis: Can Fair Trade, Organic, and Specialty Coffees Reduce Small-Scale Farmer Vulnerability in Northern Nicaragua? World Development, Amsterdã, v. 33, i. 3, p. 497-511, 2005.

BAUMGARTNER, F. R.; JONES, B. D. Agenda dynamics and policy subsystems. The journal of Politics, v. 53, i. 4, p. 1044-1074, 1991.

BUENO, N. P. A Revolução de 1930: uma sugestão de interpretação baseada na Nova Economia Institucional. Estudos Econômicos, São Paulo, v. 37, n. 2, p. 435455, 2007.

CAFÉS DA ALTA MOGIANA. Disponível em: <http://www.amsc.com.br/>. Acesso em: 20 jan. 2018.

\section{CENTRO DE DESENVOLVIMENTO TECNOLÓGICO DO CAFÉ (CETCAF).} Disponível em: <http://www.cetcaf.com.br/index.html>. Acesso em: 20 jan. 2018.

CHADDAD, F. R.; JANK, M. S.; SIDNEY, N. Repensando as políticas agrícola e agrária do Brasil. ICONE e IBMEC, p. 1-43, 2006.

COELHO, C. N. 70 anos de política agrícola no Brasil (1931-2001). Revista de política agrícola, v. 10, n. 3, p. 3-58, 2012.

CUNHA, A. S. Os 150 anos do Mapa. Revista de Política Agricola, 2010. Edição Especial.

DAVIRON, B.; PONTE, S. The Coffee Paradox: Global Markets, Commodity Trade and the Elusive Promise of Development. Zed Books, 2005. 
DELFIM NETTO, A. O problema do café no Brasil. 3. ed. São Paulo: Instituto de Pesquisas Econômicas, 1966.

DIMAGGIO, P.; POWELL, W. The Iron Cage Revisited: Institutional Isomorphism and Collective Rationality in Organizational Fields. American Sociological Review, v. 48, i. 2, p. 147-160, 1983.

EASTON, D. Uma teoria de analíse política. 2. ed. Rio de Janeiro: Zahar, 1968.

FEUERSTEIN, S. The Coffee Paradox: Global Markets. Commodity Trade and the Elusive Promise of Development. In: DAVIRON, B.; STEFANO, P. The World Economy, v. 30, i. 6, p. 1031-1032, jun. 2007.

FREY, K. Políticas públicas: um debate conceitual e reflexões referentes à prática da análise de políticas públicas no Brasil. Planejamento e políticas públicas, v. 21, p. 211-259, 2009.

FURTADO, C. Formação econômica do Brasil. 32. ed. São Paulo: Companhia das Letras, 2005.

GALA, P. A Teoria Institucional de Douglas North. Revista de Economia Política, São Paulo, 2003.

GALLEGO, R.; BARBIERI, N.; GONZÁLEZ, S. Explaining cross-regional policy variation in public sector reform: Institutions and change actors in the health sector in Spain. Public Policy and Administration, v. 32, i. 1, p. 24-44, 2017.

GEREFFI, G. et al. Introduction: Globalisation, Value Chains and Development. IDS Bulletin, New Jersey, v. 32, i. 3, p. 1-8, 2001.

GEREFFI, G.; HUMPHREY, J.; STURGEON, T. The governance of global value chains. Review of International Political Economy, London, v. 12, i. 1, p. 78-104, 2005.

GEREFFI, G. International trade and industrial upgrading in the apparel commodity chain. Journal of International Economics, Amsterdã, v. 48, i. 1, p. 37-70, 1999.

GURGEL, Â. C.; BITENCOURT, M. B.; TEIXEIRA, E. C. Impactos dos acordos de liberalização comercial Alca e Mercoeuro sobre os países membros. Revista Brasileira de Economia, v. 56, n. 2, 2002. 
HILL, M. J.; HUPE, P. L. Implementing public policy: governance in theory and practice. Sage, 2002.

HOLLOWAY, T. H. Vida e morte do convênio de Taubaté: a primeira valorização do café. Rio de Janeiro: Paz e Terra, 1978.

HUMPHREY, J.; SCHMITZ, H. Governance in Global Value Chains. IDS Bulletin, New Jersey, v. 32, i. 3, p. 19-29, 2001.

IANNI, O. Estado e planejamento econômico no Brasil (1930-1970). RAE - Revista de Administração de Empresas, v. 13, n. 1, p. 92-93, 1973.

ICAFE. Bureau de Inteligênica Compettiva do Café. Relatório Internacional de tendências do café. Lavras, v. 4, n. 2, p. 1-17, 2015.

INTERNATIONAL COFFEE ORGANIZATION. Coffee Prices. 2014. Disponível em: <http://www.ico.org/prices/pr.htm>. Acesso em: 20 jan. 2018.

JOSLING, T. E. et al. The Uruguay Round Agreement On Agriculture: An Evaluation. Commissioned Papers, 1994.

LOPES, H. C. Instituições e crescimento econômico: os modelos teóricos de Thorstein Veblen e Douglass North. Revista de Economia Política, Campinas, v. 33, n. 4, p. 619-637, dez. 2013.

LOWI, T. J. American business, public policy, case-studies, and political theory. World politics, v. 16, i. 4, p. 677-715, 1964.

LOWI, T. J. Four Systems of Policy, Politics, and Choice. Public Administration Review, v. 32, i. 4, p. 298, jul. 1972.

MANTIQUEIRA DE MINAS. Disponível em: < http://www.mantiqueirademinas. com.br/>. Acesso em: 20 jan. 2018. Acesso em: 20 jan. 2018.

MAYER, F.; GEREFFI, G. Regulation and Economic Globalization: Prospects and Limits of Private Governance. Business and Politics, Berkeley, v. 12, i. 3, p. 1-25, jan. 2010.

MINISTÉRIO DA AGRICULTURA, PECUÁRIA E ABASTECIMENTO. Plano Estratégico para o Desenvolvimento do Setor Cafeeiro. Brasilia, DF, 2012. 27 p. 
MUELLER, C. A política agrícola no Brasil: uma visão de longo prazo. Revista de política agrícola, v. 19, p. 9-23, 2010.

MUELLER, C. C. Das oligarquias agrárias ao predomínio urbano-industrial: um estudo do processo de formação de políticas agrícolas no Brasil. IPEA: INPES, 1983.

MUELLER, C.; MUELLER, B. The Evolution of Agriculture and Land Reform in Brazil, 1960-2006. In: Economic Development in Latin America. London: Palgrave Macmillan UK, 2010.

NAVARRO, Z. Meio século de transformações do mundo rural brasileiro e a ação governamental. Revista de Política Agrícola, v. 19, 2010.

ORGANIZAÇÃO PARA A COOPERAÇÃO E DESENVOLVIMENTO ECONÔMICO. Análise das políticas agrícolas do Brasil: Destaques e recomendações de políticas. Revista de Política Agricola, 2005. Edição Especial.

PASE, H. L.; MELO, C. C. Políticas públicas de transferência de renda na América Latina. Revista de Administração Pública, v. 51, n. 2, p. 312-329, 2017.

PETERS, B. G. Institutionalism and Public Policy. In: PETERS, G. B.; ZITTOUN, P. Contemporary Approaches to Public Policy. London: Palgrave Macmillan UK, 2016.

PIRES, R. R. C. Estilos de implementação e resultados de políticas públicas: fiscais do trabalho e o cumprimento da lei trabalhista no Brasil. Dados, v. 52, n. 3, p. 734769, 2009.

POLSBY, N. W. How to study community power: The pluralist alternative. The Journal of Politics, v. 22, i. 3, p. 474-484, 1960.

PONTE, S. The “Latte Revolution”? Regulation, Markets and Consumption in the Global Coffee Chain. World Development, Amsterdã, v. 30, i. 7, p. 1099-1122, 2002.

REGIÃO DAS MATAS DE MINAS. Disponível em: <http://www.matasdeminas. org.br/>. Acesso em: 20 jan. 2018.

REGIÃO DO CERRADO MINEIRO. Disponível em: <http://cerradomineiro.org/ cafe-de-atitude/cafe-produzido-com-atitude/> . Acesso em: 20 jan. 2018. 
REHBEIN, K.; SCHULER, D. A. Linking Corporate Community Programs and Political Strategies. Business \& Society, v. 54, i. 6, p. 794-821, 2015.

ROCHA, C. V. Neoinstitucionalismo como modelo de análise para as políticas públicas: algumas observações. Civitas - Revista de Ciências Sociais, v. 5, n. 1, p. 11, 2006.

RUA, M. G. Análise de políticas públicas: conceitos básicos. Washington, D.C.: Banco Interamericano de Desarrollo: INDES, 1997.

SAES, M.; NAKAZONE, D. “Cadeia: café.” In: COUTINHO, L. G.; LAPLANE, M.; LUPFER, D.; FARINA, E. (Coord.). Estudo da Competitividade de Cadeias Integradas. Brasília, DF: Instituto de Economia: Unicamp: Ministério da Ciência e Tecnologia e FINEP, 2002.

\section{SAES, M. S. M. A racionalidade econômica da regulamentação no mercado} brasileiro de café. 1995. 221 p. Tese (Doutorado em Economia)-Universidade de São Paulo, São Paulo, 1995.

SANTOS, M. A. O. Construindo a marca “Cafés do Brasil”: os desafios institucionais e seus efeitos para o posicionamento de mercado. Porto Alegre, 2015. 100 p. Dissertação (Mestrado em Agronegócio)-Universidade Federal do Rio Grande do Sul, 2015.

SECCHI, L. Políticas Públicas: Conceitos, Esquemas de Análise, Casos Práticos. São Paulo: Cengage Learning, 2011.

SOUZA, C. Políticas públicas: conceitos, tipologias e subáreas. São Paulo: Fundação Luís Eduardo Magalhães, 2002.

STONE, D. A. Causal Stories and the Formation of Policy Agendas. Political Science Quarterly, v. 104, i. 2, p. 281, 1989.

TEIXEIRA, E. C.; HOLLOWAY, G. J. Impact of the Uruguay round agreement and Mercosul on the Brazilian economy. Revista brasileira de economia, v. 52, i. 3, p. 441-462, 1998.

TIMM, J. U.; ARAUJO, M. Breve histórico do Ministério da Agricultura, Pecuária e Abastecimento. Revista de Política Agrícola, 2010. Edição Especial. 
UNITED STATES OF DEPARTAMENT AGRICULTURE. Coffee: World Markets and Trade. Disponível em: <http://usda01.library.cornell.edu/usda/current/tro>. Acesso em: 01 abr. 2017.

VALVERDE, S. R.; ZAUZA, E.; SILVA, M. da. Impactos dos diferentes acordos de liberalização do comércio internacional no setor florestal brasileiro. Scientia Forestalis, n. 55, p. 117-28, 1999.

VAN RIJSBERGEN, B. et al. The Ambivalent Impact of Coffee Certification on Farmers’ Welfare: A Matched Panel Approach for Cooperatives in Central Kenya. World Development, v. 77, p. 277-292, jan. 2016.

VERTINSKY, I.; ZHOU, D. Product and process certification - Systems, regulations and international marketing strategies. International Marketing Review, Bingley, v. 17, i. 3, p. 231-253, jun. 2000.

VILLANUEVA, L. F. A. La implementación de las políticas. Mexico: Miguel Ángel Porrúa, 1996.

WEDEKIN, I. A política agrícola brasileira em perspectiva. Revista de Política Agricola, 2005. Edição Especial.

\section{Como citar este artigo:}

\section{ABNT}

SANTOS, Marco Aurélio Dos; FERREIRA, Marco Aurélio Marques. Cafés especiais, governo e mercado: reflexões para a implementação de políticas de valorização da marca “Cafés do Brasil”. RACE, Revista de Administração, Contabilidade e Economia, Joaçaba: Ed. Unoesc, v. 17, n. 2, p. 643-666, maio/ago. 2018. Disponível em: <http://editora.unoesc.edu.br/index.php/race>. Acesso em: dia/mês/ano.

\section{APA}

Santos, M. A. Dos, \& Ferreira, M. A. M. (2018). Cafés especiais, governo e mercado: reflexões para a implementação de políticas de valorização da marca "Cafés do Brasil”. RACE, Revista de Administração, Contabilidade e Economia, 17(2), 643666. Recuperado em dia/mês/ano, de http://editora.unoesc.edu.br/index.php/race 
